\title{
Pakistani Women Knowledge, Beliefs and Attitudes towards Osteoporosis
}

\section{Sadia Shakeel ${ }^{1}$, Safila Naveed ${ }^{2 *}$, Wajiha Iffat ${ }^{1}$, Faiza Nazeer ${ }^{3}$ and Yumna Nida Yousuf ${ }^{1}$}

${ }^{1}$ Dow College of Pharmacy, Dow University of Health Sciences, Karachi, Pakistan

2Jinnah University for Women, Karachi, Pakistan

${ }^{3}$ University of Karachi, Pakistan

\begin{abstract}
The purpose of the present study was to assess knowledge of risk factors, identify beliefs and attitudes about osteoporosis, and delineate the healthy behaviors associated with osteoporosis in Pakistani women. This cross sectional study was conducted from Jan till June 2015 by adopting a pre validated questionnaire distributed to women between the age of 18 to 55 years, who had agreed and given consent to participate in the study. Descriptive statistics were used to demonstrate respondents' demographic information and their response to the questionnaire items. Pearson's chi-squared test was executed to evaluate the association of age, marital and educational status of respondents on their response to the questionnaire ( $p$ value $<0.05$ was considered as significant). The present study revealed the response rate of $65 \%$. Our findings revealed that majority of the participated women knew about osteoporosis and considered it to be a serious disease. Inspite of having knowledge the respondents are not practicing appropriate lifestyle and dietary habits to decrease their risk of osteoporosis. Such behaviors include inadequate physical activity, inadequate calcium and vitamin $D$ intake. The current study identifies that there is a need of standardized approach coupled with the well-structured health education programs to promote healthy behaviors, identify women at-risk, and encourage early diagnosis and treatment.
\end{abstract}

Keywords: Osteoporosis; Pakistani women; Knowledge

\section{Introduction}

Osteoporosis is systemic skeletal disease affecting bone density and its quality leading to bone strength weakening. It is now an established fact that low bone mineral density increases the frequency of bone fractures [1]. National guide lines for osteoporosis and its management are often available but early screening is not prevalent among many countries resulting in asymptomatic and undetected disease until fracture occurs [2]. Osteoporosis is one of the life threatening disease compromising quality of life among aging populations across the globe affecting both sexes particularly females irrespective of their race or ethnicity [3-5]. Studies conducted nationally have shown that osteoporosis is mostly prevalent in Pakistan observed after measuring the bone mineral density through ultrasound reports. There is tendency of developing osteoporosis among young and premenopausal Pakistani women diagnosed with osteopenia. Life style factors are the important parameters that assist in determination of the peak bone mass posing female at verge of developing osteoporosis [6,7]. Exercise levels, low vitamin $\mathrm{D}$ levels and poor nutrition are the contributing factors in the aggravation of condition. It is now a common practice across worldwide as well as in Pakistan that masses have shifted towards the consumption of carbonated beverages and fast food that lacks nutritious value and depriving the people with appropriate calcium intake offering low calcium intake.

Osteoporosis disease can be prevented and lessened by adopting specific healthy behaviors and by carrying out specific screening test that assist in diagnosis and its treatment $[7,8]$. Studies have suggested that osteoporosis can be prevented by taking adequate calcium intake and physical activity [9-11]. Lowe et al. carried out a study in 2011 and found out that mean calcium intake among Pakistani population was less than $50 \%$ of the WHO recommended daily intake [11]. One of the challenges faced by Pakistani population includes inadequate knowledge, these may be due to lack of guidelines, standards and low number of physicians specializing in osteoporosis prevention, diagnosis and treatment $[12,13]$.

Various researchers from different countries have already addressed on significance of knowledge awareness and perception of people about osteoporosis [14-18]. Mixed results were observed by the researchers and they were unable to develop a relationship between osteoporosis knowledge levels and its preventive behaviors [19-21]. There has been increase in the awareness of disease among the population throughout the world with the passage of time. Less is known about the perceptions, awareness, and knowledge of osteoporosis among Pakistani population. Pakistan is under developed country therefore it is necessary to minimize healthcare expenditure burden among the Pakistani population by raising the knowledge and adopting preventable measures of osteoporosis. It may be acquired by first determining the levels of knowledge and attitude of Pakistani population and then developing and implementing effective education programs [22]. Therefore; the purpose of the current study was to assess knowledge of osteoporosis, risk factors, identify beliefs and attitudes about the disease, and delineate the presence and/or absence of healthy behaviors associated with osteoporosis in Pakistani women.

\section{Materials and Methods}

\section{Study design and setting}

This cross sectional study was conducted from Jan till June 2015 by adopting a pre validated questionnaire distributed to female individuals in Karachi, Pakistan. Inclusion criteria were Pakistani female adults aged 18 to 55 years, who had agreed and given verbal consent to the study. Considering the focus of study as prevention, females younger

${ }^{*}$ Corresponding author: Safila Naveed, Faculty of Pharmacy, Jinnah University for Women, Karachi, Pakistan, Tel: 00923002621917; E-mail: safila117@yahoo.com

Received August 03, 2015; Accepted September 14, 2015; Published September 21, 2015

Citation: Shakeel S, Naveed S, Iffat W, Nazeer F, Yousuf v (2015) Pakistan Women Knowledge, Beliefs and Attitudes towards Osteoporosis. J Bioequiv Availab 7: 270-273. doi:10.4172/jbb.1000252

Copyright: (c) 2015 Shakeel S, et al. This is an open-access article distributed under the terms of the Creative Commons Attribution License, which permits unrestricted use, distribution, and reproduction in any medium, provided the original author and source are credited. 
Citation: Shakeel S, Naveed S, Iffat W, Nazeer F, Yousuf v (2015) Pakistani Women Knowledge, Beliefs and Attitudes towards Osteoporosis. J Bioequiv Availab 7: 270-273. doi:10.4172/jbb.1000252

than 18-years or more than 55 years and not willing to participate were excluded [5]. Overall $n=325$ female individuals participated in this study. Respondents were motivated to respond to given questionnaire on spot. After completion the questionnaires were consequently collected for further analysis.

\section{Data collection}

A pretested questionnaire comprising of 30 questions developed by the researchers from different published sources was administered to participants. The questionnaire was structured to obtain the demographics of the respondents, their knowledge of osteoporosis, risk factors, identify beliefs and attitudes about the disease, and delineate the presence and/or absence of healthy behaviors associated with osteoporosis.

\section{Statistical analysis}

The filled questionnaires were analyzed by using SPSS 20.0. Descriptive statistics were used to demonstrate respondents' demographic information and their response to the questionnaire items. Pearson's chi-squared test was executed to evaluate the association of age, educational and marital status of respondents on their response to the questionnaire. A p value $<0.05$ was considered as significant.

\section{Results}

\section{Demographic characteristics}

In the present study out of 500 survey questionnaires, 378 were returned back and only 325 were in useable form. Hence the response rate was $65 \%$. The demographic data is shown in Table 1 . Majority of the participants $(64.93 \%)$ belonged to the age between $36-55$ years. Among the study population, $86.15 \%$ and $70.76 \%$ were married and housewives respectively. Only $37.23 \%$ were postmenopausal women.

\section{Source of information}

On inquiring about the information source regarding health issues

\begin{tabular}{|c|c|}
\hline Characteristics & Numbers (Percentages) \\
\hline \multicolumn{2}{|c|}{ Age } \\
\hline $18-25$ & $31(9.54)$ \\
\hline $26-35$ & $65(20)$ \\
\hline $36-45$ & 105 (32.31) \\
\hline $46-55$ & $106(32.62)$ \\
\hline$>55$ & $18(5.54)$ \\
\hline \multicolumn{2}{|c|}{ Marital status } \\
\hline Married & $280(86.15)$ \\
\hline Unmarried & $45(13.84)$ \\
\hline \multicolumn{2}{|c|}{ Education } \\
\hline Illiterate & $43(13.23)$ \\
\hline Elementary & $43(13.23)$ \\
\hline Intermediate & $68(20.92)$ \\
\hline High school graduated & $41(12.61)$ \\
\hline University educated & $130(40)$ \\
\hline \multicolumn{2}{|c|}{ Working status } \\
\hline Housewife & $230(70.76)$ \\
\hline Career women & $95(29.23)$ \\
\hline \multicolumn{2}{|c|}{ Postmenopausal } \\
\hline Yes & $121(37.23)$ \\
\hline No & $204(62.76)$ \\
\hline
\end{tabular}

Table 1: Characteristics of study population

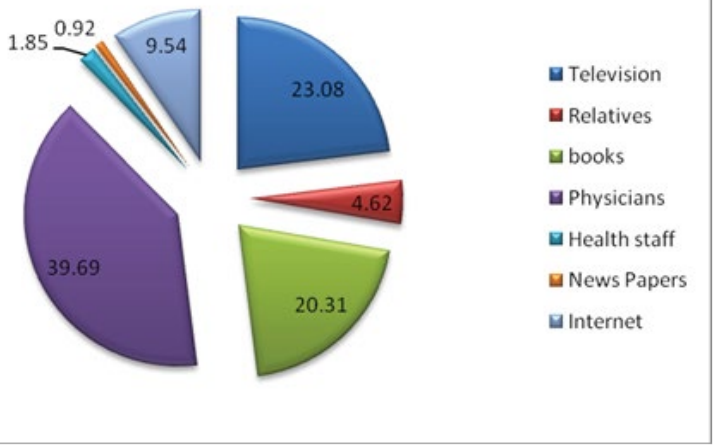

Figure 1: Participants' beliefs on sources of Health information.

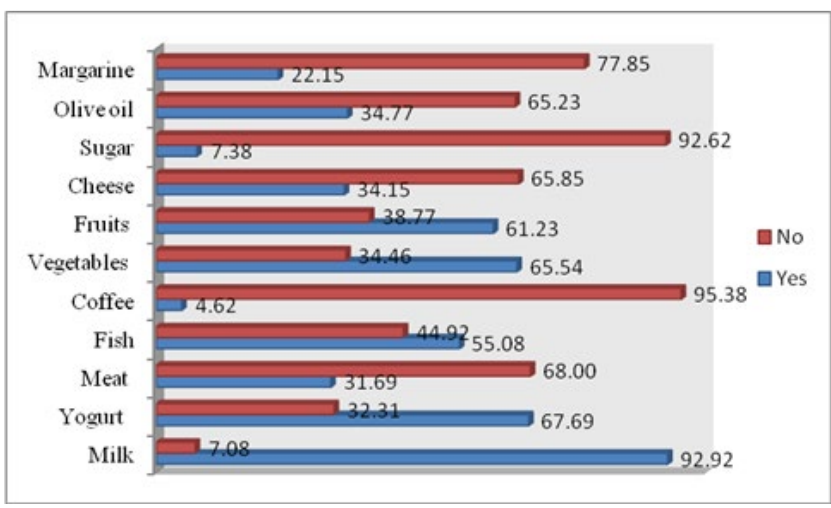

Figure 2: Respondents' practices of dietary intake.

$39.69 \%$ considered physicians to be the best and most reliable source. Television (23.08\%), books $(20.31 \%)$ and internet (9.54\%) were also believed to be the reliable sources of information (Figure 1).

\section{General knowledge regarding osteoporosis}

Responses of participants regarding the knowledge of osteoporosis are depicted in Table 2. Majority $71.48 \%$ of the participated population knew about osteoporosis and $69.5 \%$ considered it to be a serious disease. $58.15 \%$ knew that bone loss speeds up after menopause. $47.69 \%$ and $44.61 \%$ did not know that osteoporosis affect women more commonly as compared to men and is there any diagnostic test available for osteoporosis respectively.

\section{Lifestyle and nutrients intake}

Mass population $(68.92 \%)$ knew that exercise improves bone health however $58.9 \%$ exercised rarely. Near about $66 \%$ have included caffeine in their daily intake whereas, $42.76 \%$ did not know the role of smoking and caffeine in increasing the risk of osteoporosis. It was good to observed that more than $85 \%$ knew about the calcium and vitamin D rich foods and $61.53 \%$ women knew that they need more calcium after menopause than in their thirties. More than $65 \%$ did not know that estrogen replacement therapy may help decrease chances of developing osteoporosis. More than half participants $52.9 \%$ have daily direct exposure of their faces and hands to sunlight. Majority $76 \%$ did not include cheese in their daily diet and eat cheese rarely. Only $34.5 \%$ and $23.4 \%$ eat green leafy vegetables and eggs respectively on daily basis. Whereas only $35.4 \%$ agreed that they drink milk daily basis (Figure 2). Yogurt (67.69\%), vegetables (65.54\%), fruits (61.23\%) and 
Citation: Shakeel S, Naveed S, Iffat W, Nazeer F, Yousuf v (2015) Pakistani Women Knowledge, Beliefs and Attitudes towards Osteoporosis. J Bioequiv Availab 7: 270-273. doi:10.4172/jbb.1000252

\begin{tabular}{|c|c|c|c|}
\hline Items & Yes & No & Don't know \\
\hline Bone loss speeds up after menopause & $189(58.15)$ & $42(12.92)$ & $94(28.92)$ \\
\hline Osteoporosis affect men and women equally & $58(17.84)$ & $112(34.27)$ & $155(47.69)$ \\
\hline Know any diagnostic tests & $98(30.15)$ & $82(25.23)$ & $145(44.61)$ \\
\hline Exercise improves bone health & $224(68.92)$ & $32(9.84)$ & $68(20.92)$ \\
\hline Smoking and caffeine increase the risk of osteoporosis & $135(41.53)$ & $51(15.69)$ & $139(42.76)$ \\
\hline Know ways to prevent osteoporosis & $138(42.46)$ & $66(20.30)$ & $121(37.23)$ \\
\hline Know calcium and vitamin $D$ rich foods & $277(85.23)$ & $15(4.61)$ & $33(10.15)$ \\
\hline Women need more calcium after menopause than in their thirties & $200(61.53)$ & $53(16.30)$ & $72(22.15)$ \\
\hline Estrogen replacement therapy may help decrease your chances of developing osteoporosis & $52(16)$ & $59(18.15)$ & $213(65.53)$ \\
\hline Health problems caused by osteoporosis can be life-threatening & $125(38.46)$ & $74(22.76)$ & $126(38.76)$ \\
\hline
\end{tabular}

Table 2: Responses of participants regarding their knowledge of osteoporosis.

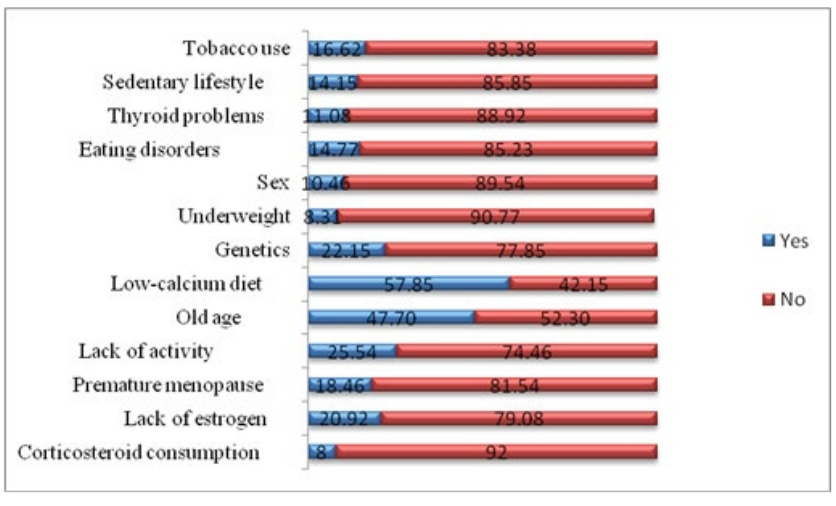

Figure 3: Respondents' belief of major risks factors.

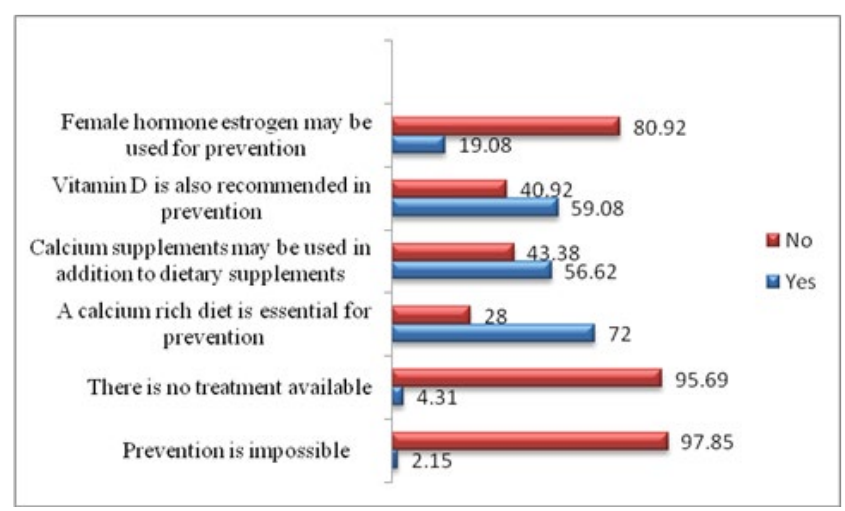

Figure 4: Respondents' beliefs of osteoporosis.

fish $(55.08 \%)$ were deemed to be preventive if consumed regularly in adequate amount.

\section{Knowledge regarding major risk factors}

On asking about the major risk factors responsible to cause osteoporosis $57.85 \%$ considered that low calcium diet is the major risk factor (Figure 3). Old age (47.7\%), lack of activity (25.54\%) and genetics $(22.15 \%)$ were also believed to be the important risk factors. Near about one third of the population considered that a calcium rich diet is essential for prevention (Figure 3).

Around $60 \%$ considered that Vitamin D is useful in prevention (Figure 4). More than 95\% did not suppose that prevention is impossible and there is no treatment available. Half of the population thought that bones cannot rebuild once they thin from osteoporosis and a woman may have osteoporosis for years but did not come to know until she breaks a bone. More than $60 \%$ assumed that if a woman has osteoporosis, something as simple as lifting a bag of groceries can break a bone. $92.2 \%$ of the population thought that milk can be the best source to prevent them from osteoporosis.

Pearson's chi-squared test was executed to evaluate the association of age and educational status of respondents on their responses. There was a very highly significant association between education and knowledge of women regarding osteoporosis $(\mathrm{p}<0.0001)$. There was also a significant association between age and knowledge of women regarding osteoporosis i.e what is osteoporosis $(\mathrm{p}=0.016)$, serious disease $(p=0.044)$, bone loss speeds up after menopause $(p=0.012)$, knowledge of diagnostic tests $(\mathrm{p}=0.003)$, smoking and caffeine increase the risk of osteoporosis $(\mathrm{p}=0.013)$ and major risks factors $(\mathrm{p}=0.001)$. No association was found between the marital status and knowledge of participants.

\section{Discussions}

There is no cure for osteoporosis, primary disease prevention through increased knowledge of risk factors and preventive behaviors is potentially important. However, our results suggest that Pakistani women are not well versed in promoting behaviors and maintain optimal bone mass and therefore not practicing the lifestyle and eating habits enough to reduce the risk of osteoporosis.

It is significant to adopt a diet rich in calcium and vitamin D owing to the fact that these nutrients work together to support healthy bone growth and maintenance. Calcium supports healthy bones, and vitamin $\mathrm{D}$ helps efficiently to absorb calcium $[6,10]$. With regard to vitamin D, numerous studies found widespread deficiency. A study in Karachi observed that $82.8 \%$ of premenopausal women were vitamin $\mathrm{D}$ deficient $(<20 \mathrm{ng} / \mathrm{mL})$ [6]. In another study, $90.1 \%$ of the younger women were vitamin $\mathrm{D}$ deficient $(<50 \mathrm{nmol} / \mathrm{L})$ [7]. Increasingly, vitamin $\mathrm{D}$ deficiency appears more common in younger than older women suggesting that peak bone mass may not be achieved, predisposing to osteoporosis later in life [7]. In current study more than $85 \%$ knew about the calcium and vitamin $\mathrm{D}$ rich foods and $61.53 \%$ women knew that they need more calcium after menopause than in their thirties. Exercise levels among this sample of women were inadequate to promote and maintain good bone health. Research has shown that exercise levels have been low in Pakistan and sedentary living is high which could be due to greater hours spent indoors with computers and watching television [4]. The elderly in Pakistan also lead a mainly sedentary lifestyle. The lack of exercise and physical activity may play a significant role in low bone mass, immobility disorders, loss of muscle mass and falls, all of which contribute to osteoporosis and related fractures [10]. In present study, 
Citation: Shakeel S, Naveed S, Iffat W, Nazeer F, Yousuf v (2015) Pakistani Women Knowledge, Beliefs and Attitudes towards Osteoporosis. J Bioequiv Availab 7: 270-273. doi:10.4172/jbb.1000252

less than one-half of women exercised at a minimal level, with only half of these women having exercised at moderate-high intensity. Research has shown that exercise helps ward off osteoporosis by strengthening bones, just as it strengthens muscles. Long-term use of oral or injected corticosteroid medications, such as prednisone and cortisone, also interferes with the bone-rebuilding process [3]. Strong bones are less likely to fracture [3]. Osteoporosis is more common in women than in men; about $80 \%$ of cases affect women. Though in our study $44.61 \%$ did not know that osteoporosis affect women more commonly as compared to men.

Menopause is manifested by a steep drop in estrogen, which is a female sex hormone that protects bones. When estrogen levels decrease, bones may lose density and become prone to fractures. It was good to observe that more than $50 \%$ of the participants knew that bone loss speeds up after menopause. Estrogen is vital to female bone health because it promotes the activity of osteoblasts, which are cells that produce bone. When estrogen levels drop during menopause, the osteoblasts aren't able to effectively produce bone [11]. Estrogen replacement therapy is used to be the only FDA-approved treatment to prevent osteoporosis [13]. There are now many other drugs and medications for osteoporosis, but estrogen remains a fairly common treatment to conserve bone mass and prevent osteoporosis-related fractures in post-menopausal women [3]. In present study more than $65 \%$ did not know that estrogen replacement therapy may help decrease chances of developing osteoporosis. A bone mineral density (BMD) test effectively detects osteoporosis. The test determines T-score, which indicates osteoporosis risk [7]. However significant proportion of study participants did not know that about this diagnostic test available for osteoporosis.

In current study $42.76 \%$ did not know the role of smoking in increasing the risk of osteoporosis. Smoking increases the risk of osteoporosis for a number of reasons. First, the chemicals found in cigarettes interfere with the normal functioning of bone cells. Also, smoking may inhibit proper calcium absorption. And lastly, smoking prevents estrogen in women from protecting their bones as it should [18].

\section{Conclusions}

The current study indicates that majority of respondents showed awareness regarding osteoporosis and its related consequences. Yet, there are some conflicts in attitudes and behavior toward factors which may contribute to the progression of disease. It identifies a more standardized approach coupled with the well-structured health education programs pointing out such gaps between knowledge and practices.

\section{Conflict of Interests}

The authors declare that there is no conflict of interests regarding the publication of this paper.

\section{References}

1. Riggs BL, Melton LJ 3rd (1995) The worldwide problem of osteoporosis: insights afforded by epidemiology. Bone 17: 505S-511S.

2. Reginster JY, Burlet N (2006) Osteoporosis: a still increasing prevalence. Bone 38: S4-9.

3. Cooley H, Jones G (2001) A population-based study of fracture incidence in southern Tasmania: lifetime fracture risk and evidence for geographic variations within the same country. Osteoporos Int 12: 124-130.

4. Jones G, Nguyen T, Sambrook PN, Kelly PJ, Gilbert C, et al. (1994) Symptomatic fracture incidence in elderly men and women: the Dubbo Osteoporosis Epidemiology Study (DOES). Osteoporos Int 4: 277-282.
5. Geller SE, Derman R (2001) Knowledge, beliefs, and risk factors for osteoporosis among African-American and Hispanic women. J Natl Med Assoc 93: 13-21.

6. Renfro J, Brown JB (1998) Understanding and preventing osteoporosis. AAOHN J 46: 181-191.

7. Grisso JA, Kelsey JL, Strom BL, O’Brien LA, Maislin G, et al. (1994) Risk factors for hip fracture in black women. The Northeast Hip Fracture Study Group. N Engl J Med 330: 1555-1559.

8. Bohannon AD, Hanlon JT, Landerman R, Gold DT (1999) Association of race and other potential risk factors with nonvertebral fractures in communitydwelling elderly women. Am J Epidemiol 149: 1002-1009.

9. NIH Consensus Development Panel on Osteoporosis Prevention, Diagnosis and Therapy (2001) Osteoporosis prevention, diagnosis, and therapy. JAMA 285: 785-795.

10. Iqbal R, Khan AH (2010) Possible causes of vitamin D deficiency (VDD) in Pakistani population residing in Pakistan. J Pak Med Assoc 60: 1-2.

11. Lowe NM, Ellahi B, Bano Q, Bangash SA, Mitra SR, et al. (2011) Dietary calcium intake, vitamin $\mathrm{D}$ status, and bone health in postmenopausal women in rural Pakistan. J Health Popul Nutr 29: 465-470.

12. Raza SA (2011) Endocrinology in Pakistan: Transcending in care of endocrinological disorders. Indian J Endocrinol Metab 15: 43-45.

13. Riaz M, Abid N, Patel MJ, Tariq M, Khan MS, et al. (2008) Knowledge about osteoporosis among healthy women attending a tertiary care hospital. J Pak Med Assoc 58: 190-194.

14. Juby A, Davis $P$ (2001) A prospective evaluation of the awareness, knowledge risk factors and current treatment of osteoporosis in a cohort of elderly subjects. Osteoporos Int 12: 617-622.

15. Gemalmaz A, Oge A (2008) Knowledge and awareness about osteoporosis and its related factors among rural Turkish women. Clin Rheumatol 27: 723 728

16. Phillipov G, Phillips PJ, Leach G, Taylor AW (1998) Public perceptions and self-reported prevalence of osteoporosis in South Australia. Osteoporos Int 8: 552-556.

17. Drozdzowska B, Pluskiewicz W, Skiba M (2004) Knowledge about osteoporosis in a cohort of Polish females: the influence of age, level of education and personal experiences. Osteoporos Int 15: 645-648.

18. Winzenberg TM, Oldenburg B, Frendin S, Jones G (2003) The design of a valid and reliable questionnaire to measure osteoporosis knowledge in women: the Osteoporosis Knowledge Assessment Tool (OKAT). BMC musculoskelet disord 4: 17

19. Taggart HM, Connor SE (1995) The relation of exercise habits to health beliefs and knowledge about osteoporosis. J Am Coll Health 44: 127-130.

20. Kasper MJ, Peterson MG, Allegrante JP, Galsworthy TD, Gutin B (1994) Knowledge, beliefs, and behaviors among college women concerning the prevention of osteoporosis. Arch Fam Med 3: 696-702.

21. Terrio K, Auld GW (2002) Osteoporosis knowledge, calcium intake, and weightbearing physical activity in three age groups of women. $\mathrm{J}$ Community Health 27: $307-320$

22. Werner $P$ (2005) Knowledge about osteoporosis: assessment, correlates and outcomes. Osteoporos Int 16: 115-127. 